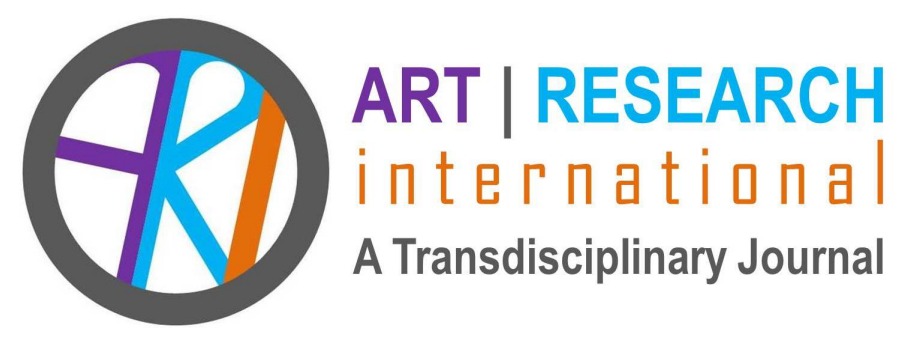

\title{
A TAPESTRIED REVIEW OF THE FULLY-VIRTUAL, NON- TRADITIONAL (UN)CONFERENCE "MAKING shiFT HAPPEN: FEMALE ACADEMICS CREATING PERSONAL AND PROFESSIONAL ALCHEMY IN THE ACADEMY," CO- CONVENED BY ALISON BLACK AND RACHAEL DWYER
}

Melinda J. Lewis

Charles Sturt University

melewis@csu.edu.au

Helen Grimmett

Monash University

helen.grimmett@monash.edu

Briony Lipton

Australian National University

briony.lipton@anu.edu.au

Susan Walsh

Mount Saint Vincent University scwalsh09@gmail.com

Barbara Bickel Southern Illinois University bickel.barbara@gmail.com 
Sandie Elsom University of the Sunshine Coast selsom@usc.edu.au

Marguerite Westacott University of the Sunshine Coast mwestaco@usc.edu.au

\section{Claire Green University of the Sunshine Coast cgreen1@usc.edu.au}

\section{Amelia Walker University of South Australia amelia.walker@unisa.edu.au}

Melinda J. Lewis is a Lecturer at Charles Sturt University, Sydney, Australia. She is completing a doctoral thesis on research and teaching relations for academic health professionals in higher education. Melinda adopts social science theoretical frames for her work and research, utilising a close-up methodology and narrative enquiry.

Helen Grimmett is a Lecturer in the Faculty of Education at Monash University, Melbourne, Australia. Her recent research has been in dialogical pedagogy and cogenerating innovative approaches to professional experience for preservice teachers through building partnerships with schools.

Briony Lipton is an academic in the School of Sociology, Australian National University, Canberra, Australia. Her recently completed thesis explored how key discourses of feminism, neoliberalism and leadership, constitute academic performativity and identity in the contemporary Australian university.

Susan Walsh is Professor Emerita of Education at Mount Saint Vincent University. She works with innovative research practices that involve the breath, contemplation, the arts, and writing as inquiry, particularly in relation to her research with female teachers. 
Barbara Bickel is an artist, researcher, writer, and educator, and Associate Professor of Art Education, Emerita at Southern Illinois University, USA. Her research interests include artsbased inquiry methods, a/r/tography, collaboration, socially-engaged art, connective aesthetics, matrixial theory, feminist art and pedagogy, and restorative and transformative learning.

Sandra (Sandie) Elsom is an Associate Lecturer in enabling education at the University of the Sunshine Coast, Australia, teaching a range of courses including ICT, Critical Thinking, Academic Writing and Statistics. Her teaching and research both focus on the integration of games into the higher education curriculum. She is particularly interested in the potential for using alternate reality games to create an engaging and effective social learning experience.

Marguerite Westacott is an Associate Lecturer in enabling education and a PhD student at the University of the Sunshine Coast, Australia. She has worked in a variety of alternative and diverse educational settings in a number of roles: teaching, leadership, counselling, consulting, curriculum development and governance. Marguerite's research and practice focus on embedding proactive and creative approaches to promoting mental health, wellbeing and career development in the curriculum and andragogy of higher education.

Claire Green is an instructor at the University of the Sunshine Coast, Australia. She is a Lecturer in the Tertiary Preparation Pathway program where she teaches ICT, Academic Skills and Critical Thinking courses. Claire also teaches Learning and Human Development to Early Childhood and Primary Education students, and the Psychology of Learning to Secondary Education students.

Amelia Walker is a Lecturer in the School of Creative Industries, University of South Australia. She is the author of four poetry collections and three poetry teaching resource books in Macmillan's All You Need to Teach series. Amelia currently teaches courses in creative writing and children's/young adult literature.

Abstract: These storied and aesthetic offerings are presented as an alchemic tapestry of experiences and responses to the conference MAKING shiFt HAPPEN. This innovative (un)conference was fully virtual, and connected us across disciplines, countries and time zones. In this review we respond to how MAKING shiFt HAPPEN offered flexible, sustainable and inclusive options for us, women in academia, to engage with meaningful ideas and with other women around the world. 
Keywords: Aesthetic responses; academic conference; women in academia; reimagining academia 
MAKING shiFt HAPPEN: Female Academics Creating Personal and Professional Alchemy in the Academy, was a transdisciplinary and global virtual conference for women in academia. It took place for 36 hours on February 4-5, AEST, 2019.

Co-convened by Dr. Alison (Ali) Black and Dr. Rachael Dwyer, University of the Sunshine Coast, Australia, the conference used video-conferencing, webinars, virtual meeting rooms, an interactive website of resources, and social media to connect 90 registrants and 16 keynote/panellist presenters (from more than 12 time zones) in processes of deep conversation, collaboration and community building. With the registrations, 19 Australian universities and 13 international universities across New Zealand, UK, Sweden, US, Canada and South Africa were represented. Participants came from a range of fields including education, health, sociology, psychology, anthropology, social work and indigenous studies. Their roles varied across the full range of academic positions: casual/sessional staff, research higher degree students, early career researchers, Associate Lecturers to Professors, Deans and Directors, librarians, and academic developers. The conference spoke to four key themes: Contemplative Beginnings; Building Caring Communities; Lived Experiences of Women in Academia; and Reimagining Academia.

(https://www.usc.edu.au/explore/structure/executive/office-of-the-deputy-vice-chancelloracademic/schools/school-of-education/making-shift-happen-virtual-conference)

\section{Melinda J. Lewis: Idle Pleasures}

This event gave me an opportunity to sit with myself and render my presence and identities into a place and space of idle pleasures that were nurturing, cathartic and restorative. We could escape into the many online/virtual and real spaces, side-stepping commotions and activities to enter a world of freedom and joy. Such idle pleasure offered the most pertinent forms of self-management in the academy, contributing to the increasing focus on student wellbeing and care. If institutions could offer what we turn to the natural world (mother nature) for - rest, healing, seeking clarity and energising - this event and caring facilitators would come close in an otherwise industrialised setting.

"In a world of non-stop toil and stress and bother, the idle pleasure can help us to live again, to enjoy ourselves, to indulge our inbuilt love of nature and sensuality and conviviality, without breaking our backs, or the bank." (Kieran \& Hodgkinson, 2008, p. viii)

Drawing from my earlier engagement in Steiner philosophy in early childhood education in the Australian context, I was drawn into the ethos and subtle sensations Ali and 
Rachael offered through colour, light, air and movement. A Eurythmy for the Academy! We could catch ourselves slipping into habits of "performing the academy," through functions and roles and adopting instrumental languages. Alternately, masks were removed, face was face online, and our transpersonal selves shone through.

I had many chances to connect, to be curious, to question. There were multiple echoes of: Who am I, as teacher, pedagogue, mother and more? I am the sort of person who would have loved to be a participant in my research on academic identities and the research-teaching nexus in higher education. I would also like to be a student in the online modules I create on supporting teachers into Indigenous Australian Cultural Competence curriculum through a deeper engagement with forms of unconscious and implicit bias, pedagogical cultural identities and place-based learning. One wonders why I research and teach the way I do?

The confluence of my spatial interests and occupational explorations in academic identities, a holistic education philosophy and Indigenous Australian Cultural Competence offer a deeper understanding of and practices with storying and narrative that may be transformational and experiential. Herein lies the shifts - just as water usually shifts around, when we sink into our humanity, we do, and this joy of returning to the source of self is what MAKING shiFt HAPPEN offered.

\section{Helen Grimmett: Two poems}

While attending MAKING shiFt HAPPEN, two short pieces of creative writing on academia and my place in it emerged. The first one was inspired as I listened to Ruth Behar and realised I had an urge to write creatively in order to purge my recent life experience and the subsequent re-evaluations of my work priorities in a potentially toxic university system.

There's a cancer in academia.

Something sinister creeping through its lymphatic system,

Growing slowly and insidiously,

Appearing OK on the surface, but doing unknown harm beneath.

Not consciously diagnosed yet, but affecting the host regardless.

There is a strange ache, something not quite right,

And then a lump is noticed....

Consciousness is raised.

Two choices....denial and carry on as usual, or courage to face the awful truth that action is required. 
Help is at hand though,

It is not a journey to traverse alone.

Others have gone before and survived,

Others are facing it alongside you.

Strength in solidarity and shared experience.

Tears and stories, Laughs and fears.

Fashioning a new path, a new way of being.

Expunging the metaphoric cancer in academia,

as I have recently expunged the very real lump in my breast.

There's a cancer in academia.

But this newly cancer-free (fingers crossed!) academic

is doubly determined not to succumb.

After getting that out of my system, and then engaging further with listening to the amazing speakers and panellists of the Reimagining Academia theme, I felt the need to follow up with something a bit lighter and more positive. The conversations over the conference and in its aftermath have been restorative and rejuvenating and at last I feel ready to leave the last few months' preoccupation with cancer behind. It took another week of percolating ideas but here is the second piece:

If the academy was music, what form would it take?

A Wagnerian opera, portraying grandiosity and elitism?

A Mozart sonata, revering structure and the classical canon?

A rousing school hymn, invoking tradition and macho brotherhood?

A Top 40 pop song, selling out to commercial demands?

Or could it be...

A traditional folk song, carrying culture across generations?

A jazz improvisation, pushing new boundaries?

A Midnight Oil anthem, protesting injustice and inspiring activism?

A campfire song, welcoming everyone to join in?

What sort of musician will I be in this academy?

Will I sing from the choir sheet? Be a diva? Or a conductor? Or a composer?

Will I play second fiddle forever? Sawing away.

Contributing, but with little recognition or scope for my own voice?

I want the music I make to be a tiny melody, quietly wending its way through corridors.

Changing the sonic landscape. 
Offering glimpses of a different tune to others stuck in their offices as I pass by.

Sometimes wistful, sometimes plaintive, often joyful,

But always offering an invitation for other voices to join with me.

In unison, or harmony, or even discordance.

If the academy is music, then WE are the music.

What songs shall we sing? What music will we make?

\section{Briony Lipton: Conference Reflections}

Monday 3 February (pre-conference)

9pm Australian Eastern Standard Time

Conferences are an important part of the working lives of academics. They are a necessity for professional development, building networks across institutions, and for sharing in ideas and knowledge, and yet for many there are significant financial, emotional, and geographical obstacles to participating in academic conferences.

MAKING shiFt HAPPEN was a 36-hour, Zoom-powered, innovative, non-traditional, transdisciplinary virtual exchange. No need to get on a plane, to check into a hotel, or Google maps the location of the conference venue. It was an (un)conference of sorts. A space specifically designed for women academics around the globe. A place for conversation, care, contribution, connection, collaboration, creativity, community and change.

At this critical stage in my aspiring early career, I simply can no longer afford to attend conferences or networking events until I secure full-time academic work. A classic early career researcher double-bind. The ethos of ShiFt of feminist collaboration, connection and slow scholarship deeply aligns with my own philosophy on academic work; work that is critical, passionate, supportive and committed to social justice, and I was grateful to learn and share with the inspiring keynotes and presenters at this innovative virtual conference: Female academics making personal and professional alchemy in the academy.

Despite its continuous programming, the pace of the 36-hour conference really connected with the ethos of the slow scholarship movement. There was enough time to prepare, engage, pause and reflect, catch up with life work and then dive back in.

I absolutely loved the concept of a digital "book pantry": an online place that holds a curated selection of scholarly articles and weblinks related to the conference themes to read 
before, during or after the conference. Tucked up in bed the night before reading articles in this virtual reading nook was a really fun way to prepare for the conference ahead.

10pm-12am Australian Eastern Standard Time

Keynote: Alison Mountz and Trina Hamilton

"Building caring communities"

Being an online conference gave me the opportunity to hear presentations by speakers that I wouldn't have necessarily gotten to see in real life. While conferences are often labelled "international" and "global" they often have a homogenising effect given that the intellectual environment within which they are held largely celebrates Anglo-American, English-speaking academic culture. Virtual conferences have the potential to challenge this.

\section{Wednesday 5 February}

(Day 2 of conference)

6-8am Australian Eastern Standard Time

Panel: Susan Walsh and Barbara Bickel

\section{"Lived experiences of women in academia"}

My toddler and partner are curled up on the sofa watching ABC's Playschool with the volume on low. I have had to resign myself to the fact that television has become a part of our morning ritual. Though, these early mornings are peaceful: An hour before the day's responsibilities kick in. An hour of snuggles, porridge, and coffee. I throw on my green floral robe, I check my reflection in the bathroom mirror. Cheeks still peachy from sleep, a quick comb of my hair, and brush of my teeth, and then I head to the kitchen to make a pot of coffee. In the kitchen the four or five minutes it takes for the stovetop espresso maker to come to the boil is sacred time. The pot grumbles on the electric cooker and I pour myself a cup and then walk to the dining table where my laptop sits waiting for me to connect to this morning's panel session. It's the fastest commute to a conference l've ever had to make. Morning sunshine dances on the wall behind me. I can't believe I'm still secretly in my pyjamas. It feels incredible. I feel comfortable and connected - fitting with themes.

Oops! My rudie-nudie-toddler wanders around behind me in full view of the webcam. I wonder if anyone will notice and hope I am not seen by the other delegates as 
unprofessional. I switch off my webcam and reposition my laptop. I'm still listening and learning.

Warm and inviting: At conferences there is invariably a hierarchy of attendees; esteemed key-note speakers, presenters, attendees, academics, students, and conference organisers. Even in traditional academic paper sessions or works-in-progress round tables there is still a hierarchy based on position, institution, and social capital. As I login to the panel session over a dozen boxes appear on the screen each with a video camera profile of conference participants and presenters. What surprised me most was the way that this virtual space challenged the hierarchy of the material conference. What struck me most was the way I was able to make eye contact with those individuals in those little boxes on my screen. It felt like the speakers were all looking and personally conversing with me.

\section{2-4pm Australian Eastern Standard Time}

\section{Keynote: Barbara Grant and Niki Harré}

\section{"Reimagining academia"}

You've registered for the conference, blocked out the time in your calendar, made all the various preparations and arrangements, and then: Sick child. My son climbs onto my lap needing cuddles. I mute the video camera and mic, but I still listen to the conversations and type in the chat box. Later, during a discussion session, I make savoury muffins for my son while he naps. Listening and talking. In some ways there's no escape from your daily routine whereas a conference most often removes you from those things, forcing you to take time for the conference, but also for yourself. I missed a few live keynotes because life got in the way, but these were recorded so I was able to go back and re-listen later.

\section{Susan Walsh: Collective Space-Time}

A number of women wove in and out of an interactive session that Barbara Bickel and I co-facilitated during the MAKING shiFt HAPPEN conference. The session was part of Theme 3, Lived Experiences of Women in Academia. Barbara and I shared glimpses of contemplative arts inquiry practices with which we engage in research, teaching, and everyday life. Together, in the space-time of this co-created session - through writing, image, and storytelling - we, as a group of women, contemplated what it means to offer and to receive blessings, particularly in the academic context. 
Below, I share a poem and painting that emerged for me during our collective space-time.

sound of the furnace

crack crack of the windows

deep cold Alberta winter afternoon

snow silence ancient gathering place

faint smell of peppermint

open hands like morning prayers

warmth of palms warmth of candle

a pain in my back

purple whirlwind radiates breathe

fingernail etches body memory

energy rising magic

received offered exchanged rose

sisters shades of yellow green

embody child's pose

forehead touches ground prayer

the breath opening back blue silver

stone in my hand

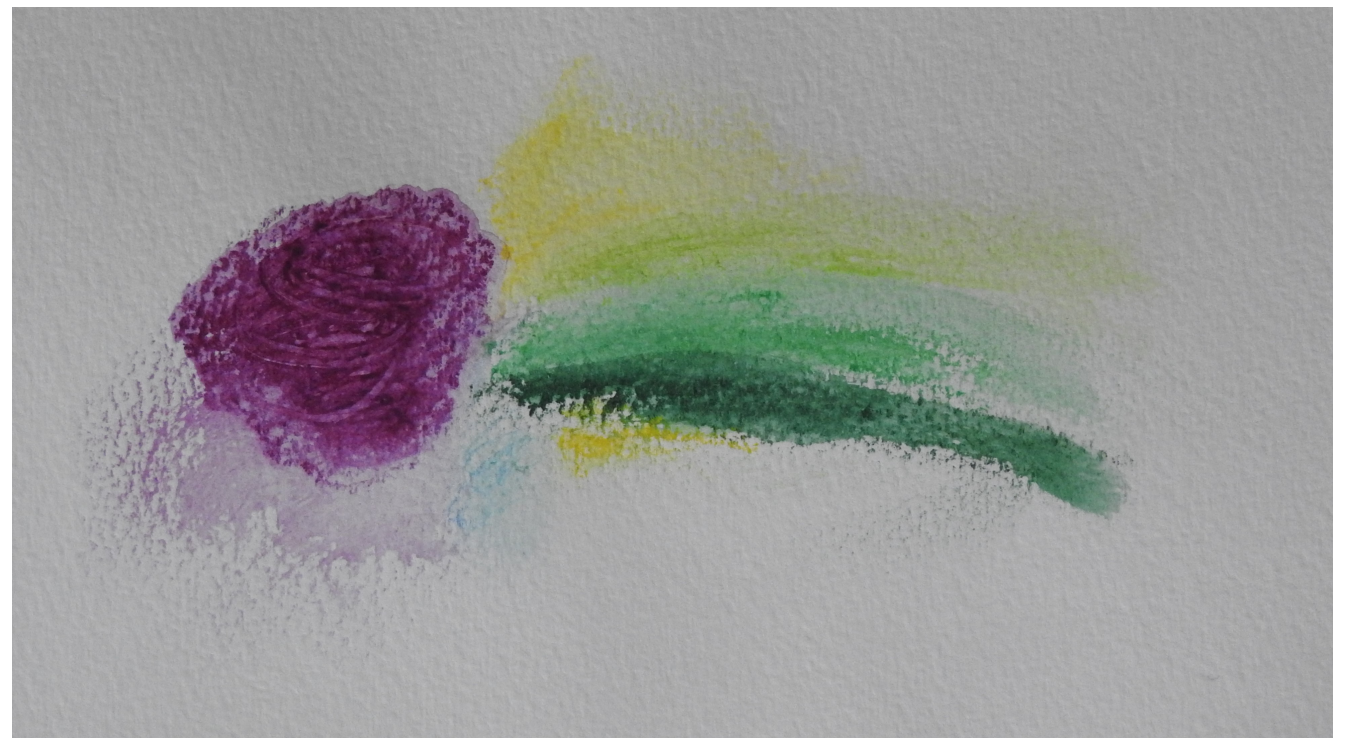

Figure 1. Walsh, S. (2019). Watercolour painting. St. Albert, Canada. 
Some of what arose for me in the session echoes experiences I have had with-in other groups of women: for example, the rose image and the rising energy. Through this practice of co-inquiry, I am reminded of how our beings wind through-and-among - and radiate among different energy fields in ways that are diffuse and relational.

Waves of appreciation to all who joined together in this session, generously offering wisdom and sharing care-filled hearts. May the benefits derived in this space-time together resound, radiate, and reverberate outward in healing ways.

\section{Barbara Bickel: Women Care}

\section{Women Care}

Sharing across the globe

Caring about each other

Caring about ourselves

How do we keep this gift flowing?

Blessing and receiving

Spirit source

Where the paper is most worn

there also is the richest beauty

An over-extended academic

my worn spots are

also the richest

to delve deep into

draw strength from

when I come home

alone

I receive again

gifts remembered

blessings shared

\section{Sandra Elsom, Marguerite Westacott, Claire Green: ShiFt}

Pockets full of post-nominals,

Esteemed gentlemen orate.

Soapboxes bulge under their rhetoric. 
At home in this space.

The crowd hears but some cannot listen, Their ears don't fit the words.

Eloquent but absent meaning.

The sonorous voices rise.

We are the spaces between the words. Transparent.

They look through us, unseeing

Quiet agitation, the breaches combine

Into clarity. Mighty. Immoveable.

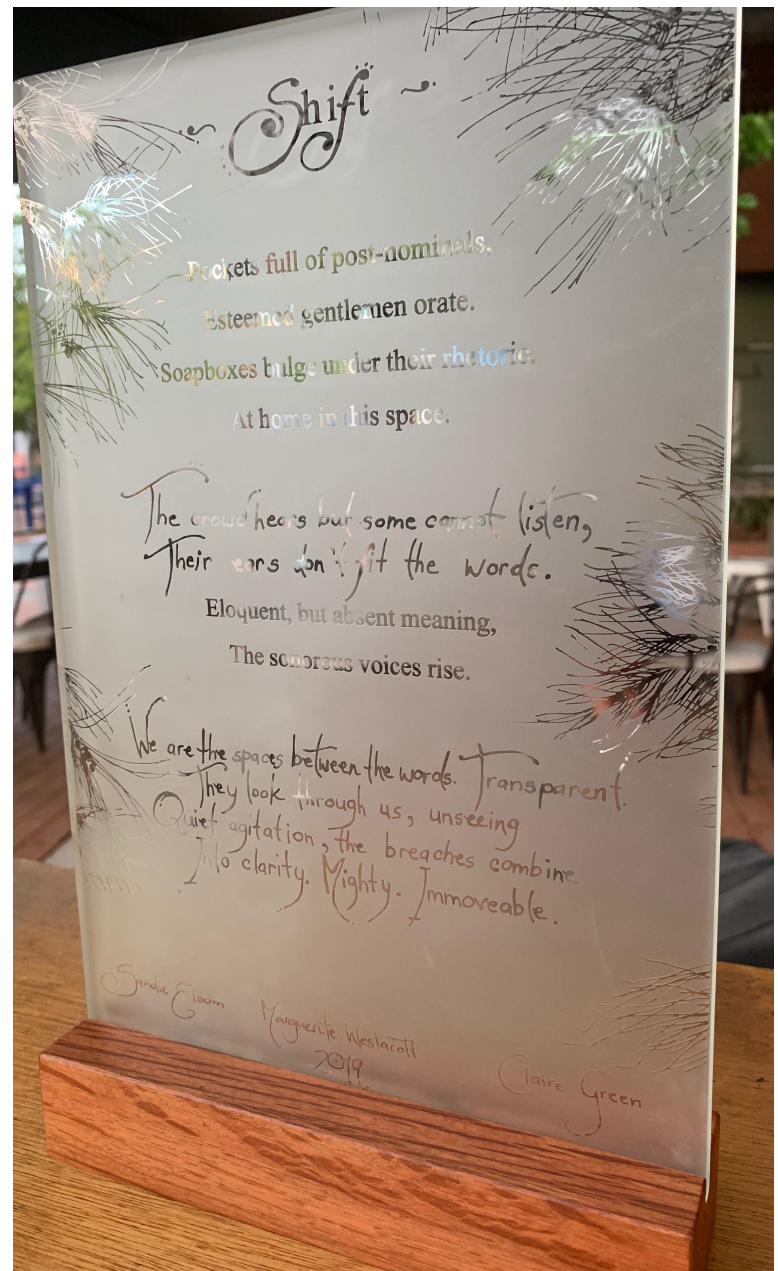

Figure 2. ShiFt, Sand-etched glass, on a Casuarina base 


\section{Artist Statement}

This collaborative piece, inspired by MAKING shiFt HAPPEN, characterises the feminine way of working, one in which our ideas, creativity, skills and resources were sifted, shared, discussed and negotiated. We are three early career academics and friends; our names appear on equal terms on the artwork - a deliberate statement of collaboration devoid of hierarchy and "refusing competitiveness" (Ruth Behar, 2019, n. p.).

The medium of glass was chosen because it represents the transparency of women situated in traditional male spaces; the viewer can choose to see the glass, or they can look straight through it. Either way, it exists. Glass is a fluid medium, even in its (deceptively) solid form it is silently evolving. We felt this reflected our experiences as early career academics who have entered academia from practice-based professional careers. Adapting to the maze of academia; "learning the language," working out "what am I supposed to do as an academic?", embracing and resisting "being professionalised," Ruth Behar's words resonated with us as we evolve to identify and avoid the moulds.

The textural contrast between the clarity of the words of the poem and the sandetched finish symbolises the shiFt as the female moves from a state of transparency to the trait of opaqueness, where she cannot be ignored. This transition is also apparent as the formal conservative font evolves into a fluid and organic handwritten text representing femininity and diversity, sitting in contrast to the uniform fonts that are reminiscent of suits and ties. The handwriting is personal and authentic; feminine. It speaks of perfection in imperfection, and an acceptance of having to let some things go.

The filament like branches of the casuarina tree are moving in and softening the hard edges of the glass, providing a delicate frame for the poem. A visceral reminder of the healing power of nature, and symbolic of the messages of self-care the conference keynote speakers emphasised throughout.

The glass sits in a solid timber base of Casuarina, which was chosen because of the complexity and beauty of its grain as well as the appropriateness of its common name, Sheoak. According to a 1914 Perth newspaper article (Anonymous, 1914), the name Sheoak was adopted because in Australia, the prefix "she" denoted "inferiority" and the Sheoak was considered an inferior timber to British oak. Therefore, in choosing Sheoak as the base for the glass, we are challenging discrimination and celebrating women's ingenuity in surviving the patriarchal system. 


\section{Amelia Walker: Wit(h)nessing shiFt}

\section{Wit(h)nessing shiFt ${ }^{1}$}

a Centro, assembling quotes from shiFt keynotes and readings:

In the academy, it's almost... a taboo, to speak from the heart ${ }^{2}$ Accounting for time... for productivity, outputs... ${ }^{3}$

How then, do we transform the university space ${ }^{4} \quad$ Time to think, write, read, research, analyze, edit, and collaborate. 5 Caring for ourselves and our communities within and beyond academia is not separate from radical social movements. ${ }^{6}$ If you can't stop the horror, shouldn't you at least document it?7 Critical thought is fundamental to who we are. ${ }^{8} \quad$ Time to engage, innovate, experiment, organize, evaluate, and inspire. ${ }^{9}$ Participants are invited to dress comfortably. ${ }^{10}$ 


\section{REFERENCES}

Anonymous. (1914, July 10). She oak or casuarina. The Western Mail. Retrieved from: https://trove.nla.gov.au/newspaper/article/37970254

Behar, R. (2019, February). How does a woman find her voice and not lose her soul in academia: Making shift happen, theme 3 keynote [Video file].

Retrieved from: https://www.youtube.com/watch?time_continue=2\&v=rjM2dtwJ3LY

Kieran, D., \& Hodgkinson, T. (Eds). (2008). The book of idle pleasures. London: Elbury Publishing. 


\section{ENDNOTES}

1 Susan Walsh and Barbara Bickel, "Wit(h)nessing" during shiFt Theme 3: Lived Experiences of Women in Academia / Panel. The word wit(h)ness originates from artist, theorist, psychoanalyst and activist Bracha Ettinger's language of matrixial borderspaces.

2 Tracey Bunda, "Welcome to Country" and Theme 1 Keynote

3 Trina Hamilton, "The Life of slow scholarship" / Theme 2 Keynote, ${ }^{4}$ Kathryn Gilbey, "Contemplating the Beginning through Contemplating the Complexity" / Black Warrior Women Scholars Speak / Theme 1 Panel ${ }_{5}^{5}$ Mountz, A., Bonds, A., Mansfield, B., Loyd, J., Hyndman, J., Walton-Roberts, M., Basu, R., Whitson, R., Hawkins, R., Hamilton, T. \& Curran, W. (2015). For slow scholarship: A feminist politics of resistance through collective action in the neoliberal university. ACME: An International Journal for Critical Geographies, 14(4), 1235-59. Retrieved from https://www.acme-journal.org/index.php/acme/article/view/1058.

6 Ranu Basu, "Living slow scholarship" / Theme 2 Panel

7 Behar, R. (1996). The vulnerable observer: Anthropology that breaks your heart (p. 2). Boston: Beacon Press.

8 Harré, N., Grant, B. M., Locke, K., \& Sturm, S. (2017). The university as an infinite game. Australian Universities' Review, 59(2), 5-13. Retrieved from https:// files.eric.ed.gov/fulltext/EJ1157040.pdf

9 Mountz, A., Bonds, A., Mansfield, B., Loyd, J., Hyndman, J., Walton-Roberts, M., Basu, R., Whitson, R., Hawkins, R., Hamilton, T. \& Curran, W. (2015). For slow scholarship: A feminist politics of resistance through collective action in the neoliberal university. ACME: An International Journal for Critical Geographies, 14(4), 1235-59. Retrieved from https://www.acme-journal.org/index.php/acme/article/view/1058. 10 From notes regarding the Zoom session with Susan Walsh and Barbara Bickel / Theme 3 Panel. 